\title{
Article
}

\section{The East Lancashire Clinic Model: Supporting care homes to understand reactive behaviours (Innovative Practice)}

Smith, Michael and Sayer, Kelly

Available at http://clok.uclan.ac.uk/31019/

Smith, Michael ORCID: 0000-0003-2631-369X and Sayer, Kelly (2021) The East Lancashire Clinic Model: Supporting care homes to understand reactive behaviours (Innovative Practice). Dementia, 20 (2). pp. 807-813. ISSN 14713012

It is advisable to refer to the publisher's version if you intend to cite from the work. http://dx.doi.org/10.1177/1471301219891021

For more information about UCLan's research in this area go to http://www.uclan.ac.uk/researchgroups/ and search for <name of research Group>.

For information about Research generally at UCLan please go to http://www.uclan.ac.uk/research/

All outputs in CLoK are protected by Intellectual Property Rights law, including Copyright law. Copyright, IPR and Moral Rights for the works on this site are retained by the individual authors and/or other copyright owners. Terms and conditions for use of this material are defined in the policies page. 


\section{Context}

At present in the UK there are around 410,000 people residing in 11,300 care homes (Competition and Markets Authority, 2017). Prince et al (2014) estimate that $69 \%$ of people in care have some form of dementia with some settings having a prevalence of around $90 \%$. Increasingly people now only go into care homes when they have a significant level of complex needs, coupled with the number of care home places reducing at the same time, it is unsurprising that there are increasing pressures on residential care services. One of the main pressures which care staff report are reactive behaviours, such as aggression, wandering, shouting, repetitive speech/behaviours and agitation, as one of their biggest difficulties. Maidment et al (2016) state that an estimated $70 \%$ of people in care homes exhibit some form of reactive behaviour. This often results in people being prescribed psychotropic medication particularly anti-psychotics, despite the risks of these treatments being well established.

There are several different terms for reactive behaviour within literature including 'challenging behaviour', 'behaviour that challenges' and 'Behavioural and Psychological Symptoms of Dementia (BPSD)', which are often used interchangeably and describe a wide range of presentations. These terms can carry a value judgement, attributing behaviours to either the staff, the person or the illness which limit understanding of the behaviour as an expression of an unmet need.

NICE guidelines (2018) recommend that non-pharmacological interventions should be the first approach used to manage reactive behaviours as opposed to psychotropic medications. Staff working in care homes are in a good position to deliver non-pharmacological interventions, however as Ervin et al (2014) identify, staff in residential settings can perceive they lack training and time to undertake these interventions. Rapaport et al (2018) also identified that systemic and cultural barriers exist which disable staff from working in different ways. These include issues around staff wellbeing, fear of scrutiny and organisational constraints.

The regulator for health and social care services in England, the Care Quality Commission (2017) has highlighted the variation in how care homes are supported by mental health services. In our locality, care homes are served by two community teams for people aged 65 and over, or with needs associated with this group, which provide input for people both in their own homes and care homes. These services cover 152 care homes spread across a wide geographic area with an average of 69 referrals a month from these homes. The clinic model pilot was developed in response to this rising demand, to provide advice and support around non-pharmacological interventions for care homes supporting people with dementia.

\section{Theoretical model}

The framework of the clinic is informed by the principles of the Newcastle model as described by James (2011) in that it aims to be 'person centred and carer focused' with an emphasis on the promotion of non-pharmacological interventions, which may also be applied to the care of other residents. Kitwood (1997) identified that a person's unique experience of dementia comprises of their personality, biography, physical health, neurological impairment and the social psychology around them. Through understanding the person's experience and view of the world, this can help us gain insight to their thoughts, feelings and behaviours. The aim of the clinics is to explore the reasons or triggers for reactive behaviours in partnership with care home staff in order to develop a shared understanding of the potential factors, such as unmet needs, which can cause them. CohenMansfield et al (2015) state that behaviours are a way of either communicating needs, trying to fulfil 
needs, or as a result of frustration caused by unmet needs. Therefore, assisting staff to identify and resolve these unmet needs the reactive behaviours will achieve the following:

Figure 1: How information feeds into the formulation

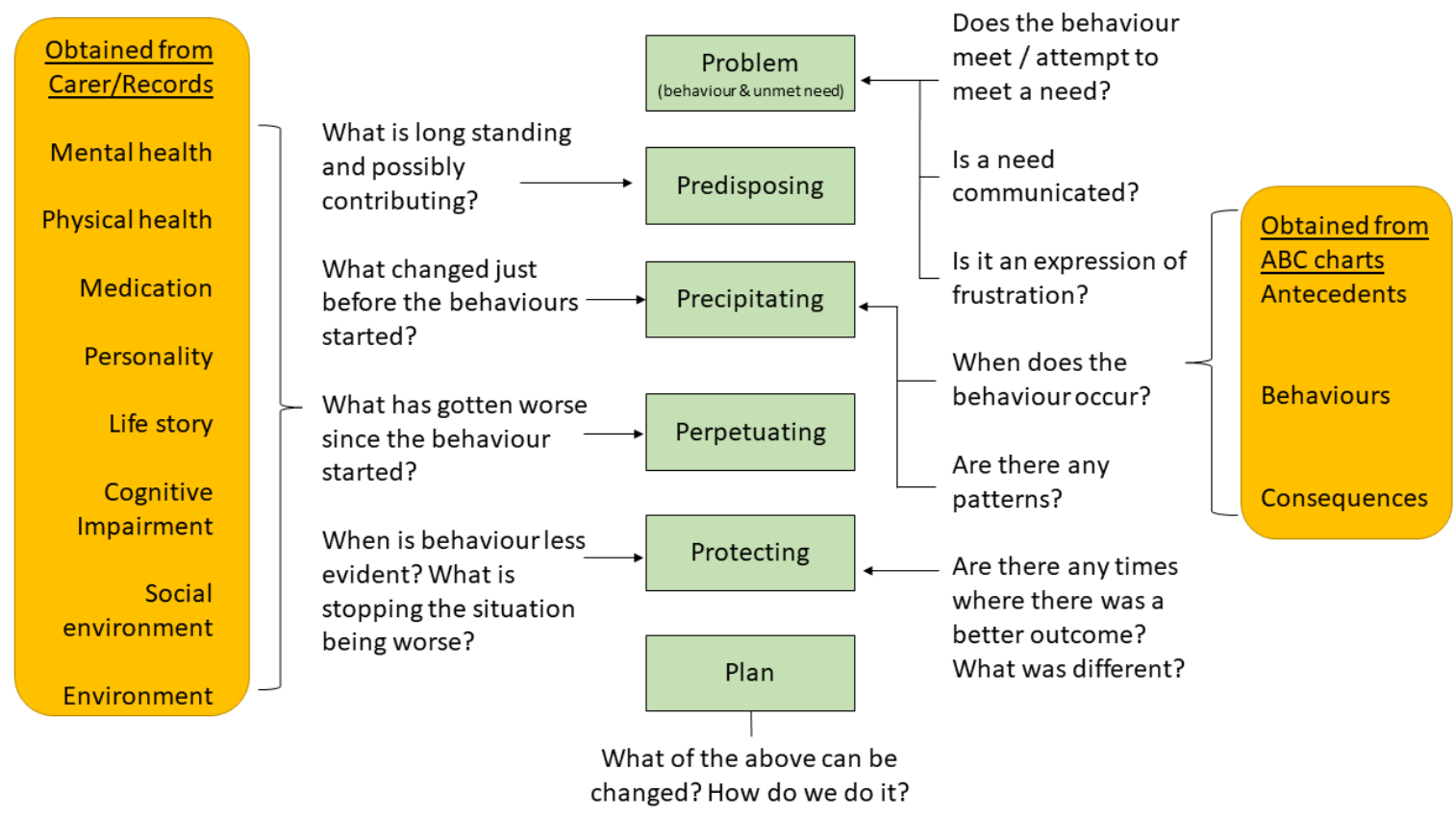

\section{Running the clinics}

For the initial phase of the pilot, four care homes were selected based on their frequent and ongoing contact with mental health services. The homes were provided with a two hour slot each for six months to discuss two to three residents each session. We asked the homes to select residents at risk of being referred to secondary mental health services. Each clinic was facilitated by a specialist Nurse and either an Occupational Therapist or Clinical Psychologist.

Residents could be discussed in the clinic if they had either a diagnosis of dementia or suspected cognitive impairment. People were excluded if they were temporarily resident, acutely unwell, receiving support from specialist mental health services already or if it was deemed that they posed a significant risk and needed even more intensive input.

Alongside broad data in terms of numbers of referrals from that unit into mental health services we gathered anonymised data around reasons for referral and outcome from the clinic, such as if the issue was resolved or if they were signposted to appropriate services (see table 2). We also utilised a questionnaire to measure staff confidence and understanding of reactive behaviour both before and after the clinic.

The key worker for the resident was asked to describe the resident's problems as staff understood them and sharing relevant history, agreement was sought prior to the clinics to share this information. The care home was asked to provide at least five behavioural charts completed over the last eight weeks and to ensure physical health investigations had been completed.

During the clinic, care home notes and behaviour charts, identifying antecedents and consequences are reviewed and considered alongside reports from staff. Using this information clinic staff start to formulate potential hypotheses for understanding these behaviours, identifying possible triggers and generating ideas for management. 
Using this information, the identified problem was formulated using a 6P formulation method (see figure 1) which helps conceptualise the problem and relevant factors which impact on this. This method asks the practitioner to consider the problem, which is often from the service user's point of view, as well as factors which trigger or worsen the reactive behaviour and those which reduce the occurrence of the behaviour, as illustrated in figure 1 and the illustrative example below. This method was chosen as it is widely used within the local NHS trust. It is felt to be easy to understand for care home staff and it translates well into care plans and risk assessments.

\section{Outcomes of the pilot}

Table 1: Referral rates from care homes

\begin{tabular}{|l|l|l|l|}
\hline Care Home & 6 Months Prior & During Clinic Period & 6 Months After \\
\hline Site 1 & 9 & 5 & 4 \\
\hline Site 2 & 6 & 0 & 5 \\
\hline Site 3 & 14 & 5 & 5 \\
\hline Site 4 & 3 & 0 & 0 \\
\hline TOTAL & 32 & 10 & 14 \\
\hline
\end{tabular}

When examining the effect the clinics had on the referral rates for the four pilot sites, it is evident that during the six months which the clinics were held, referral rates were reduced by $69 \%$ on average and have continued to be $56 \%$ lower in the six months following the completion of the project. Of the residents presented at clinic, $78 \%$ of these were categorised as some form of reactive behaviours, the remainder consisted of acute confusion, psychotic symptoms and issues with mood. Of the people presenting with reactive behaviours, $45 \%$ of these were in relation to physical aggression towards either staff or other residents.

Table 2 - Outcomes of residents presented at clinic

\begin{tabular}{|l|c|}
\hline Outcome of assessment & $\begin{array}{c}\text { Number of } \\
\text { residents }\end{array}$ \\
\hline Discharged - issue resolved & 17 \\
\hline Physical health issues identified in clinic, advised GP review and discharged. & 7 \\
\hline Medication issues identified in clinic, advised GP review and discharged. & 3 \\
\hline Secondary care mental health services needed & 5 \\
\hline Identified a need for specialist memory assessment & 2 \\
\hline Follow up in next clinic, then discharged & 1 \\
\hline TOTAL & 35 \\
\hline
\end{tabular}

As seen in Table 2, in $80 \%$ of resident's reactive behaviour discussed at clinic could be resolved with the brief input provided by the clinic model. $14 \%$ required input from secondary care mental health services and $6 \%$ were referred for specialist memory assessment.

Of those who presented with physical aggression towards others, which would typically result in a referral to mental health services, $69 \%$ of these residents were assessed and deemed appropriate for continued management within the home without secondary care services. 


\section{Illustrative example}

The care home staff described difficulty during personal care and the resident becoming distressed during the process. Through discussion we were able to identify contributory and protective factors and support staff to identify realistic ways to reduce distress.

Table 3: Example formulation

\begin{tabular}{|l|l|}
\hline Problem & Physical aggression towards staff due to lack of understanding of the situation. \\
\hline Pre-disposing & Always been a very private person, misidentifying themselves in mirrors. \\
\hline Precipitating & Personal care. \\
\hline Perpetuating & $\begin{array}{l}\text { Pain - due to refusing medications, low mood, unfamiliar staff attending to her } \\
\text { care. }\end{array}$ \\
\hline Protective & $\begin{array}{l}\text { Less distressed in the morning, more likely to accept medication in the morning, } \\
\text { enjoys singing, less distressed with familiar staff. }\end{array}$ \\
\hline Plan & $\begin{array}{l}\text { Cover mirrors in bathroom, optimise medication administration time, increase } \\
\text { preferred activities (singing), new staff to spend quality time with resident } \\
\text { outside of personal care and buddy up with experienced staff to model best } \\
\text { approach. }\end{array}$ \\
\hline
\end{tabular}

We asked staff for feedback about how useful the clinics were and any constructive feedback via questionnaire. Overwhelmingly, the care home staff expressed that the clinic was a useful resource rating it as either 'good' or 'excellent'. 100\% of respondents agreed that the clinic helped to understand the client better and $74 \%$ agreed the clinic helped to understand other clients' needs better. Some examples of written feedback are below.

"The clinics have helped clients receive help soon, and stopped them having to wait to be seen, as help can be started sooner rather than later, with advice and reassurance"

"The clinic has helped staff to better themselves in dealing with challenging residents, provided staff with better understanding of such issues and most of all such has reflected in better care for our residents".

Feedback was also requested to the structure of the clinics, the majority felt that nothing needed to be changed. One unit requested shorter but more frequent clinics whilst another requested them to continue at the same length but on a less frequent basis.

\section{Discussion}

Challenges of running the clinic

The model depends on commitment of time and staff resource by the care home which is often at a premium. Although staff were willing to participate it was identified that carers could be unprepared eg. no room to hold the clinic, resident identification left to the last minute and staff being unsure about what was expected. When the clinic was attended by a regular member of staff these issues reduced. Junior members of staff lacked confidence in terms of communicating the agreed strategies to their colleagues following the clinic discussion. Technological deficits were also identified such as unreliable Wi-Fi and access to electronic care home records. There was initial difficulty in shifting away from the traditional referral based assessment to the consultation approach. Some care homes 
continued to make referrals which had not been discussed in clinic. These referrals were then triaged and if suitable were discussed at the following clinic.

Clinic evaluation

The staff evaluation of the clinics was overall very positive. The limitations are that not every member of staff was able to provide feedback at the end of the clinic so there is a small number of completed surveys. The results of the questionnaire are also subject to respondent bias, particularly with the knowledge that they would be continuing to work with the facilitators of the clinics in future. As this was a service evaluation we were focused on the model rather than on individual service user outcomes.

Referral rates

We can see from the referral rates that the clinic model reduced referrals into secondary care service during the duration of the clinics and also for some time afterwards. It is noted however that when we combine the people discussed in the clinics with the referral rates into secondary care that more people actually received access to specialist support.

Whilst not all residents could be managed within the clinic model, this was never an expectation. With the increasing complexity of residents in 24 hour care settings there will always be role for mainstream mental health services. Whilst there is an outlay of staff time in order to run the clinic, the reactive behaviours resolved without the need for full assessment and the reduction in referrals makes the Lancashire clinic model a very efficient addition to the existing service provision.

\section{Future implications}

A follow up trial of the same size is already under way in four different care homes which has found similarly promising results. We are in discussions about widening the MDT available to the clinic, including psychiatrists, before moving to a larger project to be able to establish the impact and feasibility of the clinic model. In this we would look at effect on referral rates and potential efficiency savings.

There is a need for more research into this area to establish whether regular access to consultancy improves staff understanding and confidence in responding to reactive behaviours, improvements in interventions and what effect these have on the quality of life of people with dementia.

\section{References}

Prince, M., Knapp, M., Guerchet, M., McCrone, P., Prina, M., Comas-Herrera, A., Wittenberg, R., Adelaja, B., Hu, B., King, D., Rehill, A. \& Salimkumar, D. (2014). Dementia UK: Second Edition. London: Alzheimers Society. Available at: www.alzheimers.org.uk/dementiauk

Competition and Markets Authority. (2017). Care homes market study: Final report. London: Competition and Markets Authority. https://www.gov.uk/cma-cases/care-homes-market-

study\#final-report 
Maidment, I. D., Shaw, R. L., Killick, K., Damery, S., Hilton, A., Wilcock, J., Barnes, N., Brown, G., Gillespie, S., Fox, C., Barton, G., lliffe, S. \& Seare, N. (2016). Improving the management of behaviour that challenges associated with dementia in care homes: protocol for pharmacy-health psychology intervention feasibility study. BMJ open, 6(3), e010279.

National Institute for Health and Care Excellence (2018). Dementia: assessment, management and support for people living with dementia and their carers:. http://nice.org.uk/guidance/ng97

Cohen-Mansfield, J., Dakheel-Ali, M., Marx, M. S., Thein, K., \& Regier, N. G. (2015). Which unmet needs contribute to behavior problems in persons with advanced dementia?. Psychiatry research, 228(1), 59-64.

Kitwood, T. (1997). Dementia reconsidered: The person comes first. London: Open university press.

James, I. A. (2011). Understanding behaviour in dementia that challenges: a guide to assessment and treatment. London: Jessica Kingsley Publishers.

Rapaport, P., Livingston, G., Hamilton, O., Turner, R., Stringer, A., Robertson, S., \& Cooper, C. (2018). How do care home staff understand, manage and respond to agitation in people with dementia? A qualitative study. BMJ Open, 8(6), e022260. https://doi.org/10.1136/bmjopen-2018-022260

Ervin, K., Cross, M., \& Koschel, A. (2014). Barriers to managing behavioural and psychological symptoms of dementia: Staff perceptions. Collegian, 21(3), 201-207.

https://doi.org/10.1016/i.colegn.2013.04.002

Care Quality Commission (2017) The state of care in mental health services: 2014 to 2017. Newcastle upon Tyne: Care Quality Commission.

https://www.cqc.org.uk/sites/default/files/20170720 stateofmh report.pdf 